\title{
Satellite Studies of N(2D) Emission and Ion Chemistry in Aurorae
}

\author{
D. W. Rusch
}

Laboratory for Atmospheric and Space Physics, University of Colorado, Boulder, Colorado 80309

\author{
J-C. GERARD
}

Institut d'Astrophysique, Universite de Liège, 4200 Liège, Belgium

Space Physics Research Laboratory, University of Michigan, Ann Arbor, Michigan 48105

\begin{abstract}
The incident particle flux ion and neutral composition data taken on the AE-D satellite have been used to investigate the quantal emission of $\mathrm{N}_{2}{ }^{+}$at $4278 \mathrm{~A}, \mathrm{~N}\left({ }^{2} \mathrm{D}\right)$ at $5200 \AA$, and the ion chemistry in aurorae. The results of a time dependent auroral model have been compared to the data. The calculated $4278 \AA$ emission of $\mathrm{N}_{2}^{+}$, the $5200 \AA$ emission of $\mathrm{N}\left({ }^{2} \mathrm{D}\right)$, the densities of $\mathrm{O}_{2}^{+}, \mathrm{NO}^{+}, \mathrm{N}_{2}^{+}, \mathrm{O}^{+}$, and the electron density are generally in agreement with the measured values. These results are consistent with the branching ratios and quenching rates deduced from previous studies of the $N\left({ }^{2} \mathrm{D}\right)$ densities in the daytime, mid-latitude ionosphere. It is found that in an auroral arc, the measured atomic oxygen density is lower than predicted by the MSIS model.
\end{abstract}

\section{INTRODUCTION}

The simultaneous and broad-based measurement capability of the Atmosphere Explorer (AE) satellites allows us to obtain unique data on auroral events as the satellite passes through an active region. Two previous studies [Torr et al., 1975; Kasting and Hays, 1977] have taken advantage of the satellite's capability in order to investigate the ion chemistry and the energy degradation of electrons in aurorae. In this paper, the electron energy spectrum measured by the low-energy electron experiment (Lee) [R. Hoffman et al., 1973] and the neutral atmosphere densities of $\mathrm{N}_{2}$ and $\mathrm{O}$ measurd by the open source mass spectrometer (OSS) [Nier et al., 1973] are used as input to a time dependent model of the auroral ionosphere. The model has been previously applied to mid-latitude calculations of odd nitrogen and ion densities in the thermosphere, for comparison to satellite data [Rusch et al., 1977; Cravens et al., 1979], and to the calculation of auroral odd nitrogen and ionospheric densities, for comparison to rocket and satellite data [Gérard and Rusch, 1979].

The model is used here to calculate the ionization and dissociation rates in the atmosphere and the time dependent development of the auroral ionospheric and the odd nitrogen densities. We then compare the calculated airglow (4278 \& and $5200 \AA$ ) intensities and ionospheric densities to those measured on the satellite in an attempt to verify under auroral conditions the validity of mid-latitude odd nitrogen chemistry deduced by Rusch et al. [1975] and Frederick and Rusch [1977].

\section{DATA}

In this study we have concentrated on data from two AE-D orbits, 431 and 425 , for which perigee is located in the auroral zone during a period of bright nighttime aurorae. On one of the orbits (425), we have performed individual calculations at two different times. The basic data are shown in Figures 1 and 2. The vertical intensities of the $4278 \AA$ and $5200 \AA$ emissions are taken from the visible airglow experiment (VAE) [Hays et $a l ., 1973]$, the electron density is from the cylindrical electrostatic probe (CEP) [Brace et al., 1973], the ion densities of $\mathrm{NO}^{+}$and $\mathrm{O}_{2}{ }^{+}$are from the magnetic ion-mass spectrometer

Copyright $\odot 1980$ by the American Geophysical Union.
(Mims) [J. Hoffman et al., 1973], and the electron energy flux from Lee is displayed versus universal time and satellite altitude. In both cases, AE-D was operating in a spinning mode, cart-wheeling along its orbit. In this mode, vertical intensities may be measured by both VAE channels, although not precisely at the same time.

The VAE data were averaged in the sector of the spin within $20^{\circ}$ of the vertical. Dark count and galactic background emissions were removed by using data from the high-altitude segments of the orbits. The laboratory calibration was then applied to the data. The statistical error involved in this procedure is about $15 \%$ for the $15 \mathrm{R}$ signal measured on orbit 425 and about $5 \%$ for the $29 \mathrm{R}$ signal of orbit 431 .

The low-energy electron experiment on AE-D scans the energy range from $0.2 \mathrm{Kev}$ to $20 \mathrm{Kev}$ in 1 second. The Lee spectra were averaged over the upward-looking hemisphere during one-half of a spin period, and each sum included seven or eight spectra. The individual spectra used in the averages did not show any significant pitch angle dependence, so we assume the distribution to be isotropic at all energies. The averaged Lee spectra for the three cases studied below are shown in Figure 3 and exhibit differences in the flux distribution and total energy. Note in particular the very rapid decrease in flux at high energies and the strong 'inverted V' event of orbit 431. The collected data used for comparison to the calculation are given in Table 1, where $H$ is the satellite altitude.

The vertical distribution of the neutral atmosphere is needed as input for the calculations. To obtain this distribution we used the MSIS model [Hedin et al., 1977] and normalized the $\mathrm{N}_{2}$ density, by varying the $A p$ value in the model, to that measured by the OSS. We then normalized the atomic oxygen by multiplying the model $O$ density by the ratio of the measured $O$ density to the model $O$ density at the value of $A p$ where the $\mathrm{N}_{2}$ densities agreed. We found, in each case, that the model $\mathrm{O}$ densities had to be decreased by approximately a factor of two to match the measurement. The neutral temperature profile corresponding to the normalized MSIS model was adopted. A further difficulty arises in determining the appropriate molecular oxygen density profiles. For initial model calculations in each case we used the $\mathrm{O}_{2}$ density profile attached to the MSIS model, realizing that no attempts were made to quantitatively describe the $\mathrm{O}_{2}$ distribution in the 


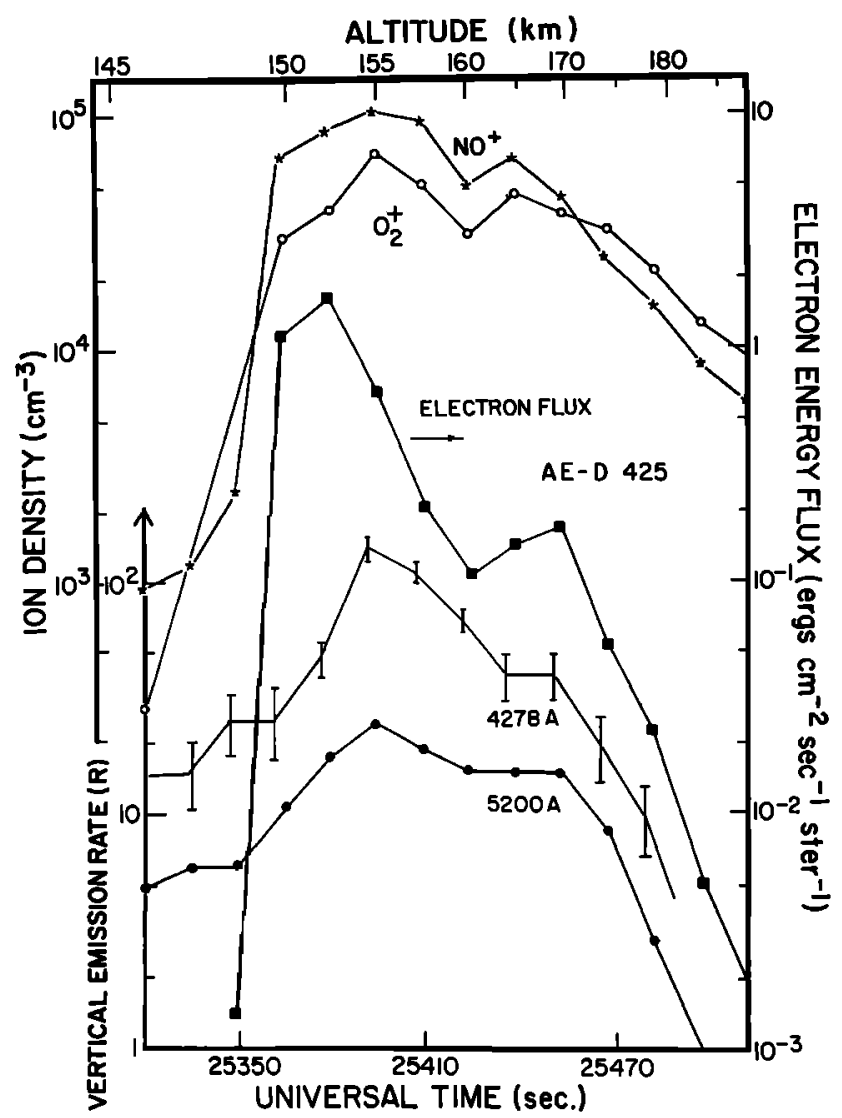

Fig. 1. The measured vertical intensities of 5200- $\AA$ and $4278-\AA$ emission, ion densities, and electron flux for AE-D orbit 425 as a function of Universal Time in seconds and satellite altitude.

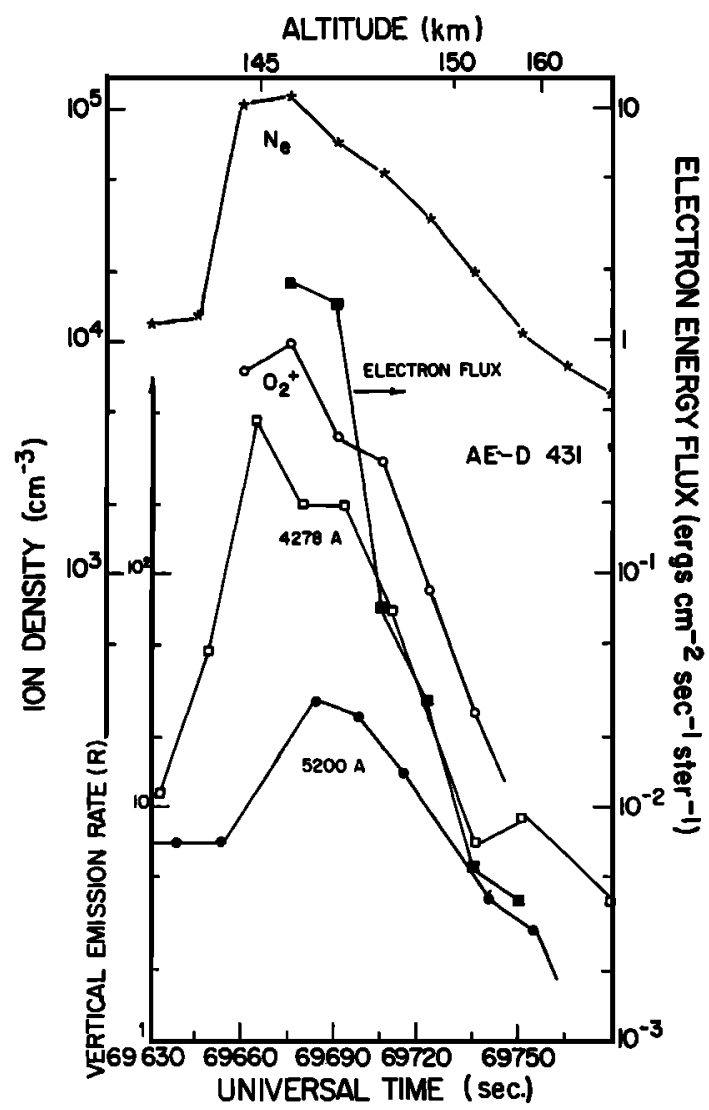

Fig. 2. Same as Figure 1 for orbit 431 , except the electron density is included.

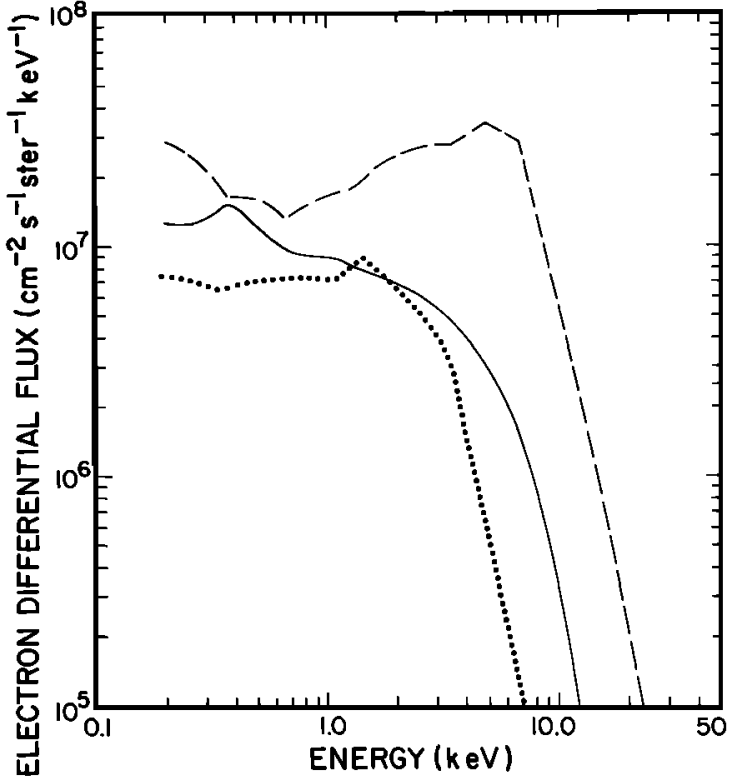

Fig. 3. The measured electron differential flux for orbit 425 at $25,425$ seconds UT ( $\cdots), 25,455$ seconds UT ( $\longrightarrow$ ), and for orbit 431 at 69,680 seconds UT (---).

model. In subsequent runs the $\mathrm{O}_{2}$ density profile was adjusted, guided by the calculated ionospheric densities and airglow emissions. The final neutral atmosphere model adopted in each case resembled that used by Gerard and Rusch [1979] in their analysis of a coordinated satellite-rocket auroral experiment.

\section{THE MODEL}

The chemical model used in these calculations has been described in several papers [Rusch et al., 1977; Cravens et al., 1979; Gerard and Rusch, 1979]. The basic features of the model are given here.

The ionization rate profile is calculated by using a method developed in Lazarev [1967] for the case of monodirectedmonoenergetic beam of electrons. This formula gives an analytical expression for the total ionization rate as a function of the penetration depth and depends on the energy of the primary electrons and the local mass density [Gérard, 1970]. The validity of this formulation was demonstrated in Gérard and Rusch [1979]. The ionization rate profile is calculated by assuming that the electron energy spectrum measured by the Lee detectors at the spacecraft altitude represents the spectrum of the primaries outside the atmosphere. This approximation would mostly affect the soft electron component (energies below $\sim 500 \mathrm{ev}$ ) whose energy is degraded above the altitude of the spacecraft. Neglect of this component would influence the calculated 4278 and $5200 \AA$ column intensities. The ionization rate is integrated over the energy spectrum, and an isotropic pitch angle distribution from $0^{\circ}$ to $80^{\circ}$ is assumed to be in agreement with the angular distribution measured by the detectors. The volume emission rate of the 4278$\AA$ band of the $\mathrm{N}_{2}{ }^{+}$first-negative system, $\eta(4278)$, is subsequently calculated from the total ionization rate $q$ by using

$$
\eta(4278)=q \frac{0.88\left[\mathrm{~N}_{2}\right]}{0.88\left[\mathrm{~N}_{2}\right]+0.5[\mathrm{O}]+\left[\mathrm{O}_{2}\right]} \cdot \frac{1}{50}
$$

The production rates of individual ions are obtained from the total ion production rate $q$ by following the method described by Vallance-Jones [1975]. The relative production of 


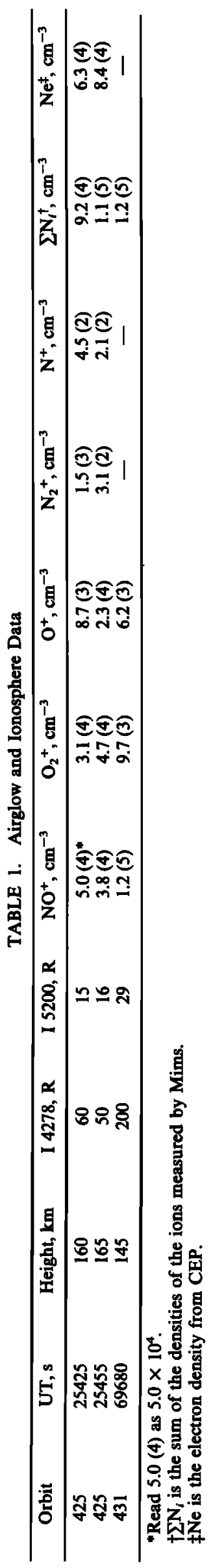

$\mathrm{O}^{+}$ions in the three lower levels ${ }^{4} \mathrm{~S},{ }^{2} \mathrm{D}$, and ${ }^{2} \mathrm{P}$ is $\mathbf{0 . 4 8}, 0.32$, and 0.20 , respectively, of the total $\mathrm{O}^{+}$production [Torr and Torr, 1978]. The ion and odd nitrogen densities are then calculated with a time-dependent model which uses a general second-order differential equation solver developed at the National Center for Atmospheric Research by Hastings and Roble [1977]. The continuity equations are solved for $\mathrm{N}_{2}^{+}$, $\mathrm{NO}^{+}, \mathrm{O}_{2}^{+}, \mathrm{N}^{+}, \mathrm{O}^{+}\left({ }^{4} \mathrm{~S}\right), \mathrm{O}^{+}\left({ }^{2} \mathrm{D}\right), \mathrm{O}^{+}\left({ }^{2} \mathrm{P}\right), \mathrm{N}\left({ }^{2} \mathrm{D}\right), \mathrm{N}\left({ }^{2} \mathrm{P}\right), \mathrm{N}\left({ }^{4} \mathrm{~S}\right)$ and NO with the chemical reactions listed in Table 2 . The NO and $N\left({ }^{4} S\right)$ calculations include molecular and eddy diffusion and appropriate flux conditions at the lower $(50 \mathrm{~km})$ and upper $(300 \mathrm{~km})$ boundaries. Most of the reaction rates and their temperature dependence that are used in the calculations have been measured in the laboratory and their values confirmed by the analysis of the AE (satellite) measurements of the thermospheric ion composition [Torr and Torr, 1978]. However, a few branching ratios and quenching rates have not been measured, and a choice must be made on the basis of the odd nitrogen daytime chemistry. The reaction of $\mathrm{N}_{2}{ }^{+}$with $\mathrm{O}$ (reaction 7) is assumed to produce only $N\left({ }^{2} D\right)$ atoms, and the dissociation of $\mathrm{N}_{2}$ by fast electron impact yields $60 \% \mathrm{~N}\left({ }^{2} \mathrm{D}\right)$, and $20 \%$ of $N\left({ }^{4} S\right)$ and $20 \% N\left({ }^{2}\right)$ in the model. In the model, effective quenching of $N\left({ }^{2} \mathrm{P}\right)$ by atomic oxygen to the $\mathrm{N}\left({ }^{2} \mathrm{D}\right)$ state makes the overall efficiency of this reaction for $N\left({ }^{2} D\right)$ production near $80 \%$. These values are in agreement with the [NI $5200 \AA$ airglow analysis by Frederick and Rusch [1977] and give satisfactory agreement with the nitric oxide densities observed in the mid-latitude lower thermosphere [Cravens et al., 1979].

\section{ANALYSIS AND RESULTS}

The measured airglow and ionospheric parameters are compared in detail to the results of the model calculations in Tables 3,4 , and 5 . The $4278-\AA$ and $5200-\AA$ emission rates listed are obtained by integrating the calculated volume emission rates above the spacecraft altitude.

Two calculations are presented for each time selected, for it is instructive to show the results as specific parameters are varied. The comments refer to the parameter variations. In all the calculations, except case 2 of Table 5 , the densities and emissions shown are for the fully developed ionosphere. The saturation time for the ionosphere at these altitudes is on the order of 500 seconds. The comparisons are difficult, of course, as we have no knowledge of the history of the event. It does appear, however, that for the two cases of orbit 425 , the ionosphere was fully developed, and for the case of orbit 431 it was not. This is consistent with the known lifetimes ( $\sim 10$ seconds) of inverted-V events, such as the one which occurred on orbit 431.

In each case the [O] density was normalized to the MSIS model, as described earlier. The objective of each calculation was to reproduce the observed optical emissions, then to see if the calculated ion densities compared favorably with the measurements. We were guided in our choice of the $\mathrm{O}_{2}$ profiles primarily by their effect on the calculated $\mathrm{O}_{2}{ }^{+}$and $\mathrm{O}^{+}$densities. We found good agreement with the airglow, the $\mathrm{NO}^{+}$ and $\mathrm{O}_{2}{ }^{+}$densities could be achieved, but $\mathrm{N}_{2}{ }^{+}$and $\mathrm{O}^{+}$were not in as good agreement. Note that it was necessary to triple the $\mathrm{O}_{2}$ densities in the cases of Tables 3 and 4, but this resulted in a calculated to measured $\mathrm{O}^{+}$ratio of 0.15 for case 2 of Table 4 . This case for orbit $\mathbf{4 3 1}$ was one of hard precipitation, probably short lived, and the results of the calculation after 6.0 seconds are in good agreement with the measurement. 
TABLE 2. Reactions and Reaction Rates

\begin{tabular}{|c|c|c|c|}
\hline & Reaction & Reaction Rate* & Source \\
\hline $\begin{array}{c}2 . \\
3 . \\
4 . \\
5 . \\
6 . \\
7 . \\
8 . \\
9 . \\
10 . \\
11 . \\
12 . \\
13 . \\
14 . \\
15 . \\
16 . \\
17 . \\
18 . \\
19 . \\
20 . \\
21 . \\
22 . \\
23 . \\
24 . \\
25 . \\
26 . \\
27 . \\
28 . \\
29 . \\
30 . \\
31 . \\
32 . \\
33 . \\
34 .\end{array}$ & 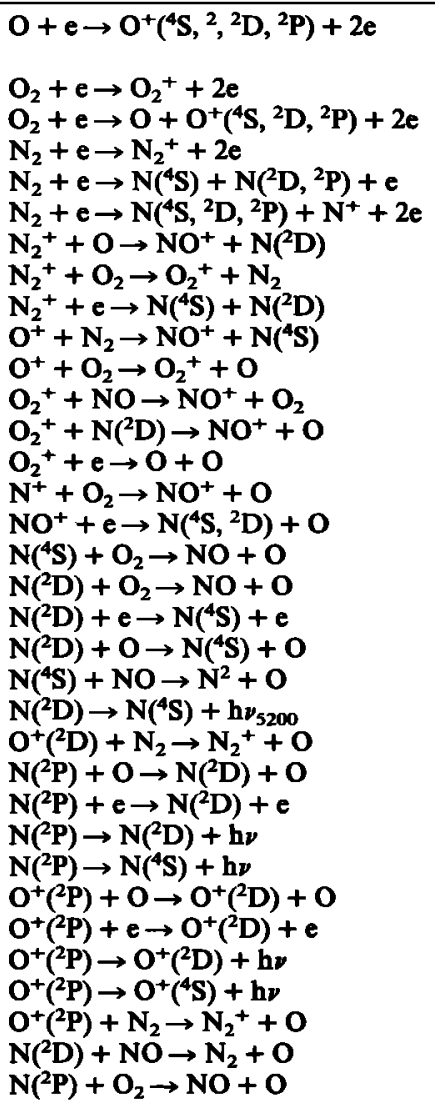 & $\begin{array}{l}\left.\left.\text { see text: } f^{4} S\right)=0.484, f^{2} \mathrm{D}\right)=0.323 \\
\quad f\left({ }^{2} \mathrm{P}\right)=0.194 \\
\text { see text } \\
\left.\left.\left.\text { see text }\left(f^{4} \mathrm{~S}\right), f^{2} \mathrm{D}\right), f^{2} \mathrm{P}\right), \text { same as } \mathrm{R} 1\right) \\
\text { see text } \\
\text { see text } \\
\text { see text } \\
1.4 \times 10^{-10}(T / 300)^{-0.44} \\
5 \times 10^{-11}(T / 300)^{-0.8} \\
1.8 \times 10^{-7}\left(T_{e} / 300\right)^{-0.39} \\
5 \times 10^{-13} \\
2 \times 10^{-11}\left(T_{n} / 300\right)^{-0.4} \\
4.4 \times 10^{-10} \\
1.8 \times 10^{-10} \\
1 \times 10^{-5} T_{e}^{-0.7} \\
2.75 \times 10^{-10} \\
4.2 \times 10^{-7}\left(T_{e} / 300\right)^{-0.85} \\
2.4 \times 10^{-11} \mathrm{exp}\left(-3975 / T_{n}\right) \\
6 \times 10^{-12} \\
6 \times 10^{-10}\left(T_{e} / 300\right)^{0.5} \\
5 \times 10^{-13} \\
2.1 \times 10^{-11} \\
A 2_{D}=1.07 \times 10^{-5} \mathrm{~s}^{-1} \\
1 \times 10^{-9} \\
1 \times 10^{-11} \\
6 \times 10^{-10}\left(T_{e} / 300\right)^{.5} \\
\mathrm{~A}=0.079 \mathrm{~s}^{-1} \\
\mathrm{~A}=0.0054 \mathrm{~s}^{-1} \\
5.2 \times 10^{-11} \\
1.89 \times 10^{-7}\left(T_{e} / 300\right)^{-0.5} \\
\mathrm{~A}=0.17 \mathrm{~s}^{-1} \\
\mathrm{~A}=0.048 \mathrm{~s}^{-1} \\
4.8 \times 10^{-10} \\
7 \times 10^{-11} \\
2.6 \times 10^{-12} \\
\end{array}$ & $\begin{array}{l}\text { McFarland et al. [1974] } \\
\text { Lindinger et al. [1974] } \\
\text { Mehr and Biondi [1969] } \\
\text { Lindinger et al. }[1974] \\
\text { McFarland et al. [1974] } \\
\text { Lindinger et al. [1974] } \\
\text { Goldan et al. [1966] } \\
\text { D. Torr et al. [1976] } \\
\text { McFarland et al. [1973] } \\
\text { Walls and Dunn [1974] } \\
\text { Wilson [1967] } \\
\text { Lin and Kaufman [1971] } \\
\text { Frederick and Rusch [1977] } \\
\text { Frederick and Rusch [1977] } \\
\text { Phillips and Schiff [1962] } \\
\text { Garstang [1956] } \\
\text { Rutherford and Vroom [1971] } \\
\text { Young and Dunn [1975] } \\
\text { Assumed } \\
\text { Garstang [1956] } \\
\text { Garstang [1956] } \\
\text { Rusch et al. [1977] } \\
\text { Henry et al. [1969] } \\
\text { Seaton and Osterbrock [1957] } \\
\text { Seaton and Osterbrock [1957] } \\
\text { Rusch et al. [1977] } \\
\text { Black et al. [1969] } \\
\text { Husain et al. [1974] }\end{array}$ \\
\hline
\end{tabular}

-Rates are in units of $\mathrm{cm}^{3} \mathrm{~s}^{-1}$ unless otherwise noted.

TABLE 3. Data and Theory for Orbit 425 at 25,425 Seconds UT

\begin{tabular}{|c|c|c|c|c|c|c|c|c|c|c|}
\hline & I 4278 & I 5200 & $\mathrm{NO}^{+}$ & $\mathrm{O}_{2}^{+}$ & $\mathbf{N}_{\mathbf{2}}{ }^{+}$ & $\mathbf{O}^{+}$ & $\mathrm{N}^{+}$ & $\Sigma \mathbf{N}_{i}$ & $\mathrm{Ne}$ & Comment \\
\hline Data & 60 & 15 & 5 (4) & $3.1(4)$ & $\begin{array}{r}1.5(3) \\
T h\end{array}$ & $8.7(3)$ & $4.5(2)$ & $9.1(4)$ & $6.3(4)$ & \\
\hline $\begin{array}{l}1 . \\
2 .\end{array}$ & $\begin{array}{l}28 \\
28\end{array}$ & $\begin{array}{l}20 \\
13\end{array}$ & $\begin{array}{l}6.2(4) \\
6.4(4)\end{array}$ & $\begin{array}{l}1.2(4) \\
1.7(4)\end{array}$ & $\begin{array}{l}6.4(2) \\
5.8(2)\end{array}$ & $\begin{array}{l}6.4(3) \\
3.6(3)\end{array}$ & $\begin{array}{l}2.4(2) \\
8.2(1)\end{array}$ & $\begin{array}{l}8.1(4) \\
8.5(4)\end{array}$ & $\begin{array}{l}8.1(4) \\
8.5(4)\end{array}$ & $\begin{array}{l}0.6 \times[\mathrm{O}] \\
0.6 \times[\mathrm{O}] \\
2.9 \times\left[\mathrm{O}_{2}\right.\end{array}$ \\
\hline
\end{tabular}

TABLE 4. Data and Theory for Orbit 425 at 25,455 Seconds UT

\begin{tabular}{|c|c|c|c|c|c|c|c|c|c|c|}
\hline & I 4278 & I 5200 & $\mathrm{NO}^{+}$ & $\mathrm{O}_{2}^{+}$ & $\mathbf{N}_{\mathbf{2}}{ }^{+}$ & $\mathbf{O}^{+}$ & $\mathbf{N}^{+}$ & $\Sigma \mathbf{N}_{i}$ & $\mathrm{Ne}$ & Comment \\
\hline Data & 50 & 16 & $3.8(4)$ & $4.7(4)$ & $\begin{array}{r}3.1(2) \\
T h\end{array}$ & $2.3(4)$ & $2.1(2)$ & $1.1(5)$ & $5.8(4)$ & \\
\hline $\begin{array}{l}1 . \\
2 .\end{array}$ & $\begin{array}{l}30 \\
29\end{array}$ & $\begin{array}{l}25 \\
17\end{array}$ & $\begin{array}{l}6.5(4) \\
6.7(4)\end{array}$ & $\begin{array}{l}1.2(4) \\
1.7(4)\end{array}$ & $\begin{array}{l}8.0(2) \\
7.4(2)\end{array}$ & $\begin{array}{l}9.2(3) \\
5.0(3)\end{array}$ & $\begin{array}{l}3.2(2) \\
1.1(2)\end{array}$ & $\begin{array}{l}8.7(4) \\
9.0(4)\end{array}$ & $\begin{array}{l}8.7(4) \\
9.0(4)\end{array}$ & $\begin{array}{l}0.6 \times[\mathrm{O}] \\
0.6 \times[\mathrm{O}] \\
3.0 \times\left[\mathrm{O}_{2}\right]\end{array}$ \\
\hline
\end{tabular}

TABLE 5. Data and Theory for Orbit 431 at 69,680 Seconds UT

\begin{tabular}{cccccccccc}
\hline & $\mathrm{I} 4278$ & $\mathrm{I} 5200$ & $\mathrm{NO}^{+}$ & $\mathrm{O}_{2}{ }^{+}$ & $\mathrm{N}_{2}{ }^{+}$ & $\mathrm{O}^{+}$ & $\mathrm{N}^{+}$ & $\Sigma \mathrm{N}_{i}$ & Comment \\
\hline Data & 200 & 29 & $1.2(5)$ & $9.7(3)$ & - & $6.2(3)$ & - & $1.2(5)$ & \\
1. & 198 & 62 & $1.6(5)$ & $2.5(4)$ & $3.7(3)$ & $1.6(4)$ & $8.4(2)$ & $2.0(5)$ & $0.5 \times[0]$ \\
2. & 198 & 26 & $8.9(4)$ & $2.7(4)$ & $1.5(3)$ & $6.5(3)$ & $3.6(2)$ & $1.2(5)$ & $0.5 \times[0]$ \\
& & & & & & & & & \\
\hline
\end{tabular}




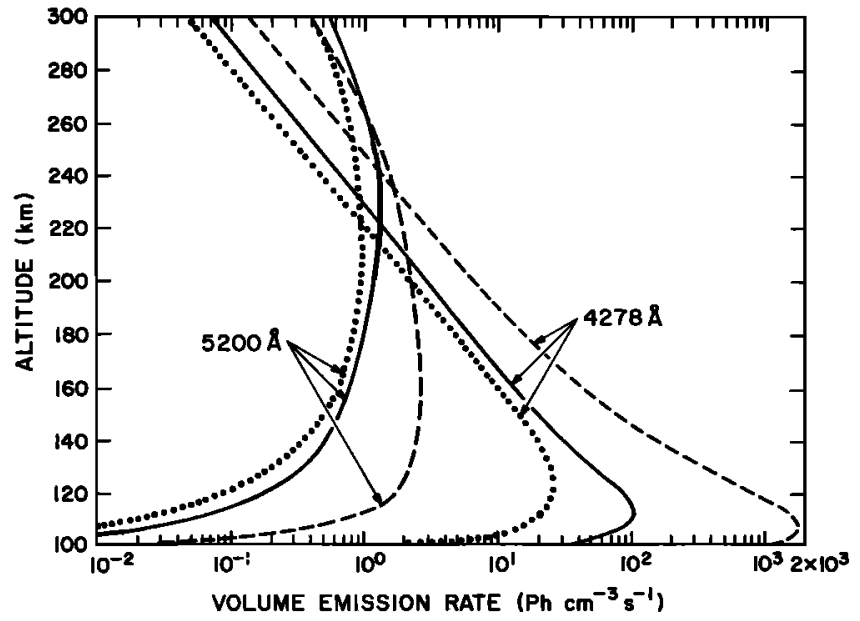

Fig. 4. The calculated altitude distribution of 4278- $\AA$ and $5200-\AA$ emission for orbit $\mathbf{4 2 5}$ at 25,425 seconds UT for case 3 of Table 3 (...), for orbit 425 at 25,455 seconds UT for case 2 of Table 4 ( $\longrightarrow$ ), for orbit 431 at 69,680 seconds UT for case 2 of Table $5(--)$.

The agreement between the calculated and measured 4278A emission rates is within a factor of two for orbit 425 . A similar discrepancy was encountered by Kasting and Hays [1977] upon comparing the $4278-\AA$ intensities measured by VAE with those calculated from the particle flux.

In Figure 4 we show the volume emission rate profiles for case 2 of Tables 3, 4, and 5 . The maximum volume emission rates for $4278-\AA$ intensities are 26,100 , and $1.6 \times 10^{3} \mathrm{ph}$ $\mathrm{cm}^{-3} \mathrm{~s}^{-1}$, which correspond to $5200-\AA$ maximum volume emission rates of $0.93,1.3$, and $2.1 \mathrm{ph} \mathrm{cm}^{-3} \mathrm{~s}^{-1}$, respectively. This indicates that the shape of the incident energy flux and the neutral atmosphere play important roles in determining the $5200-A$ intensity profile. Note that the peak intensity of 5200 for orbit 431 occurs at $140 \mathrm{~km}$.

\section{Discussion AND CONCLUSIONS}

Detailed comparison of the production and loss rates for $\mathbf{N}\left({ }^{2} \mathrm{D}\right)$ in the aurora and in the mid-latitude daytime ionosphere [Frederick and Rusch, 1977] show that the dominant sources of $N\left({ }^{2} D\right)$ are different in the aurorae. The production rates for $N\left({ }^{2} D\right)$ are displayed in Figure 5 for case 2 of orbit 425 , at 25,425 seconds for the individual reactions. In the daytime, dissociative recombination of $\mathrm{NO}^{+}$(reaction 16) and ionization interchange of $\mathrm{N}_{2}{ }^{+}$with $\mathrm{O}$ (reaction 7) dominate at altitudes above $150 \mathrm{~km}$, and dissociative excitation of $\mathrm{N}_{2}$ by energetic electrons (reaction 5 ) is a $10 \%$ source. In the aurora, at the altitudes studied, the three sources are very nearly equal if the efficiency for production of $N\left({ }^{2} D\right)$ by reaction 5 is effectively $\mathbf{8 0 \%}$. Also, the major quenching species in the standard model in the aurora is molecular oxygen due to the relatively low atomic oxygen density. At mid-latitudes, quenching by atomic oxygen dominates in the 200 - to $240-\mathrm{km}$ region, a fact which led Frederick and Rusch [1977] to infer the low quenching rate of $N\left({ }^{2} D\right)$ by $O$.

In the aurora, about four nitrogen atoms are produced for each $\mathbf{N}_{2}$ ionization. Two nitrogen atoms are produced from each $\mathrm{N}_{2}{ }^{+}$ion, one from reaction 7 and one from the subsequent $\mathrm{NO}^{+}$recombination, reaction 16 . Further, the total cros section for the dissociation of $\mathrm{N}_{2}$ by electrons [Winters, 1966] is nearly equal to the ionization cross section, so the rate of ionization of $N_{2}$ is nearly equal to the rate of $N_{2}$ dis-

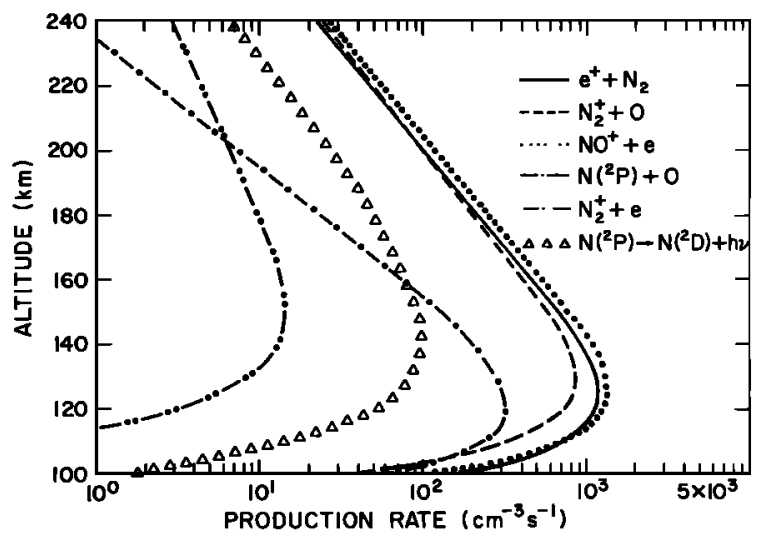

Fig. 5. The calculated production rates for $N\left({ }^{2} D\right)$ for case 2 orbit 425 at 25,425 seconds.

sociation. Thus four $\mathbf{N}$ atoms are produced for each $\mathbf{N}_{\mathbf{2}}$ ionization.

If we accept the efficiencies for the production of $N\left({ }^{2} \mathrm{D}\right)$ by reactions $5,6,7$, and 16 as $80 \%, 80 \%, 100 \%$, and $80 \%$, respectively, the total auroral efficiency for all sources for $N\left({ }^{2} D\right)$ production is $83 \%$. This extremely high efficiency is required to satisfy the $5200-\AA$ measurements. The efficiency for production of $N\left({ }^{2} D\right)$ by reaction 26 has been measured in the laboratory by Kley et al. [1977], and the $100 \%$ efficiency for reaction 6 is required by the dayglow measurements [Frederick and Rusch, 1977] and supported by the theoretical calculations of Oran et al. [1975]. However, there has been no firm indication of the combined efficiency of reactions 5 and 6 . From this study we infer that this efficiency must be large, probably near $80 \%$, in agreement with the value inferred from studies of the nitric oxide density in the lower thermosphere [Cravens et al., 1979].

The calculations are subject to uncertainties, because the auroral histories are unknown, and time variations in the electron precipitation during the measurement period are difficult to discern.

We conclude that the chemistry adopted adequately explains the measured $5200-\AA$ emission in the aurora. This chemistry is consistent with the requirements of the daytime mid-latitude ionosphere and measurements of the $N\left({ }^{2} D\right)$ density in the mid-latitude dayglow.

Acknowledgments. This work was supported by the National Aeronautics and Space Administration under grants NSG5372 at the University of Colorado and NAS5-23006 at the University of Michigan. One of the authors (J-C. Gérard) is supported by the Belgian Foundation for Scientific Research (FNRS). We thank the National Center for Atmospheric Research for computer time. The National Center for Atmospheric Research is supported by the National Science Foundation.

The Editor thanks J. F. Noxon and A. Vallance-Jones for their assistance in evaluating this paper.

\section{REFERENCES}

Black, G., T. G. Slanger, G. A. St. John, and R. A. Young, Vacuum ultraviolet photolysis of $\mathrm{N}_{2} \mathrm{O}, 4$, Deactivation of $\mathrm{N}\left({ }^{2} \mathrm{D}\right), \mathrm{J}$. Chem. Phys., 51, 116, 1969.

Brace, L. H., R. T. Theis, and A. Dalganno, The cylindrical electrostatic probe for Atmosphere Explorer-C,-D, and -E, Radio Sci., 8, 341, 1973.

Cravens, T. E., J-C. Gerard, A. I. Stewart, and D. W. Rusch, The latitudinal gradient of nitric oxide in the lower thermosphere, $J$. Geophys. Res., 84, 2675, 1979.

Frederick, J. E., and D. W. Rusch, On the chemistry of metastable atomic nitrogen in the $F$ region deduced from simultaneous satellite 
measurements of the $5200-\AA$ airglow and atmospheric composition, J. Geophys. Res., 82, 3509, 1977.

Garstang, R. A., Transition probabilities of auroral lines, in The Airglow and Aurorae, edited by E. B. Armstrong, p. 324, Pergamon, New York, 1956.

Gérard, J-C., Metastable oxygen ions distribution and related optical emission in aurora, Ann. Geophys., 26, 777, 1970.

Gérard, J-C., and D. W. Rusch, The theory of the auroral ionosphere: Comparison of a time-dependent model with composition measurements, J. Geophys. Res., 84, 4335, 1979.

Goldan, P. D., A. L. Schmeltekopf, F. C. Fehsenfeld, H. I. Schiff, and E. E. Ferguson, Thermal energy ion-neutral reaction rates, 2 , Some reactions of ionospheric interest, J. Chem. Phys., 44, 4095, 1966.

Hastings, J. T., and R. G. Roble, An automatic technique for solving coupled vector systems of non-linear parabolic partial differential equations in one space dimension, Planet. Space Sci., 25, 209, 1977.

Hays, P. B., G. Carignan, B. C. Kennedy, G. G. Shepherd, and J. C. G. Walker, The visible-airglow experiment on atmosphere explorer, Radio Sci., 8, 369, 1973.

Hedin, A. E., C. A. Reber, G. P. Newton, N. W. Spencer, H. C. Brinton, H. G. Mayr, and W. E. Potter, A global thermospheric model based on mass spectrometer and incoherent scatter data MSIS, 2, Composition, J. Geophys. Res., 82, 2148, 1977.

Henry, R. J. W., P. G. Burke, and A. L. Sinfailam, Scattering of electrons by $\mathrm{C}, \mathrm{N}, \mathrm{O}, \mathrm{N}^{+}, \mathrm{O}^{+}$, and $\mathrm{O}^{++}$, Phys. Rev., 178, 218, 1969.

Hoffman, J. H., W. B. Hanson, C. R. Lippincott, and E. E. Ferguson, The magnetic ion-mass spectrometer on atmosphere explorer, $R a$ dio Sci., 8, 315, 1973.

Hoffman, R. A., J. L. Burch, R. W. Janetzke, J. F. MoChesney, S. H. Way, and D. S. Evans, Low-energy electron experiment for Atmosphere Explorer-C and -D, Radio Sci., 8, 393, 1973.

Husain, D., S. K. Mitra, and A. N. Young, Kinetic study of electronically excited atoms $N\left(2^{2} D_{J}, 2^{2} P_{J}\right)$ by attenuation of atomic resonance radiation in the vacuum ultraviolet, $J$. Chem. Soc., Faraday Trans. II, 70, 1721, 1974.

Kasting, J. F., and P. B. Hays, A comparison between $\mathbf{N}_{2}+4278-\AA$ emission and electron energy flux in the auroral zone, $J$. Geophys. Res., 82, 3319, 1977.

Kley, D., G. M. Lawrence, and E. J. Stone, The yield of N( $\left.{ }^{2} D\right)$ atoms in the dissociative recombination of $\mathrm{NO}^{+}, J$. Chem. Phys., 66, 4157, 1977.

Lazarev, V. I., Absorption of the energy of an electron beam in the upper atmosphere, Geomagn. Aeron., 7, 219, 1967.

Lin, C-L., and F. Kaufman, Reactions of metastable nitrogen atoms, J. Chem. Phys., 53, 3760, 1971.

Lindinger, W., F. C. Fehsenfeld, A. L. Schmeltekopf, and E. E. Ferguson, Temperature dependence of some ionospheric ion-neutral reactions from $300^{\circ}$ to $900^{\circ} \mathrm{K}, J$. Geophys. Res., 79, 4753, 1974.

McFarland, M., D. L. Albritton, F. C. Fehsenfeld, E. E. Ferguson, and A. L. Schmeltekopf, A flow-drift technique for ion mobility and ion-molecule rate constant measurements, J. Chem. Phys., 59, 6620, 1973.
McFarland, M., D. L. Albritton, F. C. Fehsenfeld, E. E. Ferguson, and A. L. Schmeltekopf, Energy dependence and branching ratio of the $\mathrm{N}_{2}{ }^{+}+\mathrm{O}$ reaction, J. Geophys. Res., 79, 2925, 1974.

Mehr, F. J. and M. A. Biondi, Electron temperature dependence of recombination of $\mathrm{O}_{2}{ }^{+}$and $\mathrm{N}_{2}{ }^{+}$ions with electrons, Phys. Rev., 181, 264, 1969.

Nier, A. O., W. E. Potter, D. R. Hickman, and K. Mauersberger, The open-source neutral-mass spectrometer on Atmosphere Explorer-C, -D, and -E, Radio Sci., 8, 271, 1973.

Oran, E. S., P. S. Julienne, and D. F. Strobel, The aeronomy of odd nitrogen in the thermosphere, $J$. Geophys. Res., 80, 3068, 1975.

Phillips, L. F., and H. I. Schiff, Mass spectrometer studies of atom reactions, 1, Reactions in the atomic nitrogen-ozone system, J. Chem. Phys., 36, 1509, 1962.

Rusch, D. W., A. I. Stewart, P. B. Hays, and J. H. Hoffman, The NI (5200-A) dayglow, J. Geophys. Res., 80, 2300, 1975.

Rusch, D. W., T. E. Cravens, G. R. Carignan, A. I. Stewart, and J-C. Gerrard, A theoretical model of odd nitrogen in the earth's thermosphere and mesosphere, EOS Trans AGU, 58, 1198, 1977.

Rutherford, J. A., and D. G. Vroom, Effect of metastable $\mathrm{O}^{+}\left({ }^{2} \mathrm{D}\right)$ on reactions of $\mathrm{O}^{+}$with nitrogen molecules, $J$. Chem. Phys., 55, 5622, 1971.

Seaton, M. J., and D. E. Osterbrock, Relative (OII) intensities in gaseous nebulae, Astrophys. J., 125, 66, 1957.

Torr, D. G., and M. R. Torr, Review of rate coefficients of ionic reactions determined from measurements made by the Atmosphere Explorer satellites, Rev. Geophys. Space Phys., 16, 327, 1978.

Torr, D. G., M. R. Torr, J. C. G. Walker, A. O. Nier, L. H. Brace, and H. C. Brinton, Recombination of $\mathrm{O}_{2}^{+}$in the ionosphere, $J$. Geophys. Res., 81, 5578, 1976.

Torr, M. R., D. G. Torr, R. A. Hoffman, W. B. Hanson, J. H. Hoffman, W. K. Peterson, and J. C. G. Walker, An auroral F-region study using in situ measurements by the Atmosphere Explorer-C satellite, Planet. Space Sci, 23, 1669, 1975.

Vallance-Jones, A., A model for the excitation of electron aurora and some applications, Can. J. Phys., 53, 2267, 1975.

Walls, F. L. and G. H. Dunn, Measurements of total cross sections for electron recombination with $\mathrm{NO}^{+}$and $\mathrm{O}_{2}^{+}$using storage techniques, J. Geophys. Res., 79, $1911,1974$.

Wilson, W. E., Rate constant for the reaction $\mathrm{N}+\mathrm{O}_{2} \rightarrow \mathrm{NO}+\mathrm{O}, J$. Chem. Phys., 46, 2017, 1967.

Winters, H. F., Ionic absorption and dissociation cross section for nitrogen, J. Chem. Phys., 44, 1472, 1966.

Young, R. A., and O. J. Dunn, The excitation and quenching of N('P), J. Chem. Phys., 63, 1150, 1975.

(Received August 22, 1979; revised November 14, 1979; accepted November 15, 1979.) 